\title{
To: Biason-Lauber A, Boehm B, Lang-Muritano M et al. (2005) Association of childhood type 1 diabetes mellitus with a variant of PAX4: possible link to beta cell regenerative capacity. Diabetologia 48:900-905
}

Received: 8 July 2005 / Accepted: 16 July 2005 / Published online: 13 August 2005

(C) Springer-Verlag 2005

\begin{abstract}
Abbreviations HWE: Hardy-Weinberg equilibrium . TDT: transmission/disequilibrium test
\end{abstract}

To the Editor:

PAX4 is involved in pancreatic beta cell development and maintenance of the endocrine pancreas, which makes PAX4 an interesting candidate gene for diabetes. However, the genetic studies performed to date have produced conflicting results. Screening of French MODY and late-onset type 2 diabetes families showed no linkage between MODY or type 2 diabetes and markers of PAX4 [1]. PAX4 markers showed no linkage to type 2 diabetes in Ashkenazi Jews [2]. A Japanese study identified a missense mutation (Arg121Trp) in PAX4 [3]. The mutant protein exhibited loss of function relative to the wild type and seemed to be associated with type 2 diabetes. Another study from Japan reported that this mutant was associated with late-onset type 2 diabetes and was correlated with impaired first-phase insulin secretion [4].

One study has observed an association between PAX4 haplotypes and type 1 diabetes, but no significant linkage between type 1 diabetes and the $P A X 4$ region [5]. A recent case-control study reported a strong association between childhood type 1 diabetes and a Pro321His variant of PAX4 [6]. Functional studies of the Pro321His variant in a

T. Gylvin · R. Bergholdt · J. Nerup · F. Pociot $(\bowtie)$

Steno Diabetes Center,

Niels Steensens Vej 2-4,

2820 Gentofte, Denmark

e-mail: fpoc@steno.dk

Tel.: +45-44439371

Fax: $+45-44437313$

\section{J. Nerup}

Department of Endocrinology and Autoimmune Diseases,

University of Lund,

Malmö, Sweden

F. Pociot

Institute for Clinical Science, University of Lund,

Malmö, Sweden beta cell line showed significant differences in proliferation capability in response to glucose stimulation, whereas no differences were seen in studies of this variant in two nonbeta cell lines [6]. These interesting findings prompted us to examine the single nucleotide polymorphism $(1168 \mathrm{C}>\mathrm{A}$, Pro321His) in a Danish family collection of type 1 diabetes families.

The PAX4 variant was examined in a type 1 diabetes family collection comprising 270 Danish type 1 diabetes families (1,461 individuals, 99 simplex families and 171 multiplex families). Type 1 diabetes was diagnosed according to the criteria adopted by the World Health Organization in 1985 [7]; the median age at onset for probands was 11 years (range $0-29$ years). We also genotyped 91 nondiabetic unrelated Danish Caucasians with no family history of diabetes.

Genomic DNA analysis of PAX4 was carried out by PCR-RFLP, as described previously [1,6]. The amplicon has one HhpI restriction site independent of the polymorphism, which was used as an internal control for the enzymatic digestion reaction. In addition, a number of DNAs representing each of the three genotypes were sequenced to confirm the results of the PCR-RFLP assay. Association was evaluated by a modified version of the transmission/ disequilibrium test (TDT), which uses the data for all of the affected children [8].

Allele and genotype frequencies were calculated for the probands $(n=270)$ and parents $(n=478)$ in the 270 families. The observed genotype frequencies in parents did not deviate from Hardy-Weinberg equilibrium (HWE). TDT analyses showed random transmission to both affected ( $z$ score: $0.954, p=0.34)$ and unaffected offspring $\left(\chi^{2}=0.06, p=0.81\right)$ (Table 1).

Thus, we were unable to detect an association between the PAX4 variant and type 1 diabetes in our study population using the TDT. These findings are in contrast with those of a recent study by Biason-Lauber et al. [6], in which a highly significant association was found between the $1168 \mathrm{C}>\mathrm{A} P A X 4$ polymorphism and type 1 diabetes using a 
Table 1 Transmission patterns from heterozygous parents to affected and unaffected offspring

\begin{tabular}{lllll}
\hline & \multicolumn{2}{l}{ TDT analysis: affected offspring } & \multicolumn{2}{c}{ TDT analysis: unaffected offspring } \\
\cline { 2 - 3 } \cline { 5 - 5 } & Transmissions & Non-transmissions & Transmissions & Non-transmissions \\
\hline C allele & 123 & 113 & 72 & 75 \\
A allele & 113 & 123 & 75 & 72 \\
\hline
\end{tabular}

Random transmission was observed to both affected and unaffected offspring

${ }^{\mathrm{a} C}$ Combined $z$ score: $0.954, p=0.34$

${ }^{\mathrm{b}} \chi^{2}=0.06, p=0.81$

case-control design. The genotype distribution among the two type 1 diabetes populations included in their study is comparable to that in the probands in our study. The present family study is sufficiently powered [9] to detect differences in transmission patterns corresponding to a relative risk of 3.75 for developing type 1 diabetes for carriers of the $\mathrm{C} / \mathrm{C}$ genotype and a five-fold lower chance of developing type 1 diabetes for subjects having the $\mathrm{A} / \mathrm{C}$ genotype, as reported by Biason-Lauber et al. [6].

The validity of genetic association studies depends considerably on the use of appropriate controls. Theoretically, disease-free control groups from outbred populations should be in HWE. In the study by Biason-Lauber et al., both of the control populations studied (424 Swiss and 646 German control subjects) deviate from HWE as evaluated by the $\chi^{2}$ test. HWE is not simply a theoretical issue: deviations can signal important problems, errors or peculiarities in the analysed data set, e.g. population stratification or genotyping error. An important advantage of the TDT is that it avoids the erroneous disease associations that may result from population stratification [9]. We attempted to replicate the observation by Biason-Lauber et al. [6] in a family collection to complement the case-control design and to address possible population stratification. In our families the parent generation followed HWE. We also genotyped a small number of non-diabetic control subjects $(n=91)$; the $\mathrm{C} / \mathrm{C}$ genotype had an even higher frequency among these individuals $(0.75)$ than in the other groups but were in HWE. Two other studies have investigated this variant in control populations $[1,3]$. In both studies the control populations were in HWE and had genotype frequencies similar to those reported in the present study. Whether the observation by Biason-Lauber et al. is true or caused by, for example, population stratification, we cannot establish. Furthermore, we cannot exclude the possibility of an age-dependent effect. However, the average age at onset in our study is most likely comparable with that of subjects included in the study by Biason-Lauber et al. (childhood diabetes) [6]. This stresses the importance of testing for HWE even in populations expected to be homogeneous. Interestingly, a number of recent studies have shown that the reporting of HWE in genetic association studies published in different journals varied from 20-69\% [10]. Furthermore, deviations from HWE occurred in $10-35 \%$ of the total number of studies. In several cases these deviations were not reported by the authors, leading to poten- tially misleading conclusions [10]. The findings from the functional studies by Biason-Lauber et al. [6] on the transcriptional activity and DNA binding of PAX4 suggest some influence on beta cell regeneration and are therefore of interest. Whether the $1168 \mathrm{C}>\mathrm{A}$ variant by itself explains such positive findings is uncertain, and our data do not support a role of this variant in type 1 diabetes. We suggest that additional studies of larger family collections or very large case-control collections are needed.

Acknowledgements The skilful technical assistance of B. B Jørgensen and S. Munch is highly appreciated. We thank the Danish Society for Diabetes in Childhood (DSBD) and the Danish IDDM Epidemiology and Genetics Group for the collection of type 1 diabetes families. This study was supported by the Danish Medical Research Council (grant no. 22-030494).

\section{Reference}

1. Dupont S, Vionnet N, Chèvre et al (1999) No evidence of linkage or diabetes-associated mutations in the transcription factors BETA2/NEUROD1 and PAX4 in Type II diabetes in France. Diabetologia 42:480-484

2. Tao T, Wasson J, Bernal-Mizrachi E et al (1998) Isolation and characterization of the human PAX4 gene. Diabetes 47:1650 1653

3. Shimajiri Y, Sanke T, Furuta H et al (2001) A missense mutation of Pax4 gene (R121W) is associated with type 2 diabetes in Japanese. Diabetes 50:2864-2869

4. Kanatsuka A, Tokuyama,Y, Nozaki O et al (2002) Beta-cell dysfunction in late-onset diabetic subjects carrying homozygous mutation in transcription factors NeuroD1 and Pax4. Metabolism 51:1161-1165

5. Holm P, Rydlander B, Luthman H et al (2004) Interaction and association analysis of a type 1 diabetes susceptibility locus on chromosome $5 \mathrm{q} 11-\mathrm{q} 13$ and the $7 \mathrm{q} 32$ chromosomal region in Scandinavian families. Diabetes 53:1584-1591

6. Biason-Lauber A, Boehm B, Lang-Muritano M et al (2005) Association of childhood type 1 diabetes mellitus with a variant of PAX4: possible link to beta cell regenerative capacity. Diabetologia 48:900-905

7. World Health Organization (1985) Diabetes mellitus: report of a WHO study group (Technical Report Series no. 727). WHO, Geneva

8. Martin ER, Kaplan NL, Weir BS (1997) Tests for linkage and association in nuclear families. Am J Hum Genet 61:439-448

9. McGinnis R (2002) Power and efficiency of the TDT and casecontrol design for association scans. Behav Genet 32:135-144

10. Salanti G, Amountza G, Ntzani EE, Ioannidis JPA (2005) Hardy-Weinberg equilibrium in genetic association studies: an empirical evaluation of reporting, deviations, and power. Eur J Hum Genet 13:840-848 